Brazilian Journal

of Chemical

ISSN 0104-6632

Printed in Brazil

Engineering

www.scielo.br/bjce

Vol. 35, No. 02, pp. 441 - 458, April - June, 2018

dx.doi.org/10.1590/0104-6632.20180352s20160592

(cc) BY

\title{
MODEL COMPARISON TO DESCRIBE BHK-21 CELL GROWTH AND METABOLISM IN STIRRED TANK BIOREACTORS OPERATED IN BATCH MODE
}

\author{
Roger Sartori ${ }^{1}$, Jaci Leme ${ }^{2}$, Celso Pereira Caricati ${ }^{2}$, Aldo Tonso ${ }^{3}$ and \\ Eutimio Gustavo Fernández Núñez ${ }^{1,3,4 *}$
}

\author{
'Departamento de Ciências Biológicas, Universidade Estadual Paulista "Júlio de Mesquita Filho" \\ Campus-Assis. Avenida Dom Antonio, 2100, 19806-900, Assis, SP - Brazil \\ ${ }^{2}$ Laboratório Especial de Pesquisa e Desenvolvimento em Imunológicos Veterinários, Instituto \\ Butantan. Av. Vital Brasil, 1500, 05503-900, São Paulo, SP-Brazil \\ ${ }^{3}$ Laboratório de Células Animais, Departamento de Engenharia Química, Escola Politécnica, \\ Universidade de São Paulo. Av. Prof. Luciano Gualberto, trav. 3, 380, 05508-900, São Paulo, SP- \\ Brazil \\ ${ }^{4}$ Centro de Ciências Naturais e Humanas (CCNH), Universidade Federal do ABC, Avenida dos \\ Estados, 5001, 09210-580, Santo André, SP-Brazil.
}

(Submitted: October 17, 2016; Revised: December 24, 2016; Accepted: February 6, 2017)

\begin{abstract}
Baby Hamster Kidney cells (BHK-21) are commonly used in research and the biopharmaceutical industry. This work aimed to model the kinetic performance in batch operation mode of BHK-21 cells cultured in two stirred tank configurations using different dissolved oxygen concentrations and $\mathrm{pH}$ control strategies. Viable and dead cell concentrations, as well as glucose, glutamine, lactate and ammonium concentrations, were monitored. Statistical multiple linear regression, logistic equation and multiplicative Monod kinetic models were fitted. Statistical models for viable cells concentration as a function of nutrient and metabolite concentrations were significant $\left(\mathrm{R}^{2}>0.91\right)$. Logistic model parameters: intrinsic growth rate, cell density level in the medium and time for reaching maximum cell concentrations were within $0.061-0.083 \mathrm{~h}^{-1}, 1.85-5.39 \times 10^{9}$ cell L$^{-1}$ and 52$90 \mathrm{~h}$ ranges, respectively. A Monod-type model was satisfactorily fitted to the experimental data. Relative errors were lower than $10 \%$ for six monitored state variables in most of the assessed experimental conditions. The three models developed in this work can be used in bioprocesses involving BHK-21 with good fitting.
\end{abstract}

Keywords: batch operation, bioprocess engineering, mammalian cell culture, mathematical modelling, stirred tank bioreactor.

\section{INTRODUCTION}

Biologically derived drugs have become a major part of the current pharmaceutical industry. Among the industrial cell lines used for producing approved biologics, the mammalian cell lines encompass $51 \%$ of them (Kantardjieff and Zhou, 2014). These hosts are utilized in products with extensive post-translational modifications in order to ensure drug safety and efficacy (Kantardjieff and Zhou, 2014; Pörtner, 2014). The list of the most used mammalian cell lines at large scale includes Chinese hamster ovary $(\mathrm{CHO})$ cells, baby hamster kidney (BHK) cells, mouse myeloma cells comprising NS0 and SP2/0, hybridomas, and

*Corresponding author: eutimiocu@yahoo.com 
human cell lines (HEK293, HT-1080) (Kantardjieff and Zhou, 2014; Zhu, 2012). Among these cell lines, BHK-21 has found applications at large scale in veterinarian viral vaccines against foot-and-mouth disease and rabies virus, as well as heterologous protein production (Factor VIII) (Auniņš, 2010; Palomares and Ramírez, 2009).

Mammalian cell cultures are expensive and complex as a rule (Kontoravdi et al., 2013). In this context, it is important to develop robust, controlled and optimized processes at large scale in order to diminish costs associated with process failures and maximize productivity. The use of model-based methodologies is one of the tools utilized for this purpose. The application of model-based techniques can also facilitate the decrease of experimental work by indicating the most informative experiments (Koutinas et al., 2013). In this direction, regulatory agencies stimulate model-based platforms for process development by means of quality by design (QbD) initiative (Kontoravdi et al., 2013; Nagashima et al., 2013; Tomba et al., 2013). According to QbD the quality must be "built into" the product and ensured since its design stage, through an extensive mechanistic understanding of the connection between product quality attributes and process parameters (Tomba et al., 2013).

Process models, used within the chemical engineering research area and extended to biopharmaceutical production, can be categorized as qualitative, mathematical, and statistical models. Mathematical models can be further subdivided into mechanistic and empirical models or classified by the level of structure and segregation considered. The simplest mechanistic models are unstructured and non-segregated. Such models treat the cell as a single homogeneous unit and describe the cell population as identical average cells. Monod-type kinetic models that are used in bioconversion processes belong to this type of model. They can explain correctly experimental data without high computational difficulties as required in structured and segregated models. The specific growth and death rates are usually modeled using this approach as a function of nutrient and metabolite concentrations (Craven et al., 2013).

Other alternatives to Monod-type kinetic models, with less mathematical complexity, have been developed such as semi-empirical logistic equations and empirical statistical regression models for mammalian cell cultures (Craven et al., 2013). The logistic equation developed by Verhlust provides a means to limit growth with time introducing an inhibition term in the original Malthus equation, which is cell concentration dependent. This model takes into account the finite resources for growth (Blanch and Clark, 1997). Two main parameters must be defined experimentally in the logistic model: the overall saturation constant (upper limit for cell concentration) and intrinsic growth rate constant. This modelling approach describes bioconversions with fewer or similar parameters than Monod-type models, but it does not have extrapolation capability. On the other hand, the statistical regression models allow estimating viable cell concentrations based on nutrient (glucose and glutamine) and metabolites (ammonium and lactate) in culture broth by multiple linear regression. In order to enhance fitting quality of the model, the original values of viable cells concentration are frequently transformed by a natural logarithm function (Craven et al., 2013). The build of cell growth statistical models from chemical substance concentrations in culture broth has a singular importance within the current Process Analytical Technology context, where on-line and atline monitoring systems for these parameters, through different spectroscopic techniques, are developed with relative ease (Leme et al., 2014). Nevertheless, the application of this model is limited to batch operation mode, and physical interpretations of model parameters are difficult to define (Craven et al., 2013).

On the other hand, the bioreactor configuration and process parameters, such as $\mathrm{pH}$, temperature, dissolved oxygen concentration, inoculum quality and concentration, define the cell growth and yield in bioconversion vessels (Streefland et al., 2013; Núñez et al., 2013). Therefore, values for parameters associated with process models could change with modifications in both sources of cell environmental shifts. However, the real effect of critical process parameters on model kinetic parameter values for each mammalian cell host must be defined for specific industrial applications of them.

Thus, this work aimed to fit a Monod-type kinetic model, semi-empirical logistic equation models and empirical statistical regression models for BHK-21 cell batch culture executed in different stirred tank configurations, dissolved oxygen concentrations and $\mathrm{pH}$ control strategies and determine the impact of these factors on parameters of process models for cell growth and its systemic relation with metabolism when possible. 


\section{MATERIALS AND METHODS}

\section{Cell line and culture medium}

BHK-21 (C-13) cells (Sigma-Aldrich ECACC Cell Lines, Lyon, France) adapted to single cell suspension culture were kindly supplied by Dr. Renaud Wagner from Ecole Superieure Biotechnologie de Strasbourg, France. The detailed culture medium composition was previously defined (Núñez et al., 2013). Briefly, the culture medium was composed of the following ingredients (volume/volume percent): Iscove's Modified Dulbecco Medium with glutamine and Phenol red 45.5\%; High glucose Dulbecco's Modified Eagle Medium 45.5\%; heat inactivated fetal bovine serum $5.0 \% ; 10 \% \mathrm{~m} / \mathrm{v}$ Pluronic F-68 aqueous solution $2 \%$; and $4 \mathrm{mM}$ glutamine aqueous solution $2 \%$.

\section{Inoculum preparation}

One milliliter of BHK-21 cells $\left(2 \times 10^{6}\right.$ cell $\left./ \mathrm{mL}\right)$ was thawed and placed in a $75 \mathrm{~cm}^{2}$ tissue culture flask (vertical position) with $30 \mathrm{~mL}$ of culture medium for growing. Four days afterwards, the cell suspension was used to inoculate $\left(0.12 \times 10^{6} \mathrm{cell} / \mathrm{mL}\right)$ consecutively other tissue culture flasks of 25 and 75 $\mathrm{cm}^{2}$; enough culture medium was added to reach final cellular suspensions of 10 and $30 \mathrm{~mL}$, respectively. Inoculum for bioreactors was generated from 100 and $250 \mathrm{~mL}$ spinner flasks (Bellco Glass, Vineland, NJ), with working volumes of 50 and $100 \mathrm{~mL}$, respectively; the stirring speed was maintained at $30 \mathrm{rpm}$ (SciEra quad drive stirrer system with a stirrer, Bellco Biotechnology, Vineland, NJ). Spinners were seeded $\left(0.25 \times 10^{6} \mathrm{cell} / \mathrm{mL}\right)$ from $75 \mathrm{~cm}^{2}$ tissue culture flask in the exponential phase. After $72 \mathrm{~h}$, the inoculums for bioreactors were ready; the cell concentration and viability in spinners were $4.27 \pm 0.85 \times 10^{6}$ cell $/ \mathrm{mL}$ and $100 \%$, respectively. All the procedures described in this section were performed at $37{ }^{\circ} \mathrm{C}$ and $5 \%$ of carbon dioxide atmosphere.

\section{Bioreactor batch cultures}

Eleven batch experiments in stirred tank bioreactors were carried out in a $5 \mathrm{~L}$ Celligen (New Brunswick Scientific, Edison, NJ) without aeration cage and $2 \mathrm{~L}$ Bioflo 110 (New Brunswick Scientific, Edison, NJ) at $37^{\circ} \mathrm{C}$, agitation at $80 \mathrm{rpm}$. Bioreactors operated with 2 and $1 \mathrm{~L}$ working volumes, respectively, with initial cell concentration of $0.25 \times 10^{6} \mathrm{cell} / \mathrm{mL}$. The aeration in both bioreactors was performed by sparging. Both configurations were studied to define the impact of two different aeration- homogenization systems: classical (Bioflo 110) and rotating gas sparger (Celligen) in stirred tank bioreactors on kinetic parameters of culture.

Three experiments were performed in Celligen at different dissolved oxygen concentrations, 10, 30 and $50 \%$ of air saturation with $400 \mathrm{~mL} / \mathrm{min}$ volumetric gas flow (using a variable gas mixture composed of $\mathrm{CO}_{2}, \mathrm{~N}_{2}, \mathrm{O}_{2}$ and air). The $\mathrm{pH}$ was controlled at 7.2 just with $\mathrm{CO}_{2}$ according to the buffering capacity of the $\mathrm{NaHCO}_{3}-\mathrm{CO}_{2}$ system. Similar operational conditions were explored including Bioflo 110; additionally, 70\% (air saturation) dissolved oxygen concentration was studied; the volumetric gas flow used was $200 \mathrm{~mL} / \mathrm{min}$.

Further, two experiments were performed in duplicate in Bioflo 110 at 30 and 50\% air saturation, controlling $\mathrm{pH}$ at 7.2 throughout the culture, adding gas $\mathrm{CO}_{2}$ or $\mathrm{NaHCO}_{3}$ solution $(8 \% \mathrm{~m} / \mathrm{v})$ when required. The cultures in Celligen were not conducted under regulated $\mathrm{pH}$ conditions because of the absence of the $\mathrm{pH}$ control loop in this bioreactor by design.

Samples for monitoring of cell growth, nutrient consumptions, and metabolite productions were withdrawn twice a day.

\section{Cell counting}

Total cell concentrations were measured using the hemocytometer method (Neubauer improved counting chamber, Precicolor HBG, Germany) with proper sample dilution with Phosphate Buffered Saline. Viable and dead cell concentration was quantified using the trypan blue exclusion method (Freshney, 2010). The sample dilutions were adjusted to count a number of cells within the range of 30-50 per quadrant in the counting chamber (eight quadrants were counted to calculate the average cell concentration) and only one researcher measured cell concentration over the course of the entire experimental activities.

\section{Nutrient and metabolite analysis}

Samples from culture broth were centrifuged at $750 \times \mathrm{g}$ for 4 minutes. Subsequently, supernatants were filtered and frozen for later analysis of nutrients and metabolites (Núñez, et al., 2013). Glucose, lactate, glutamine and glutamate concentrations from supernant samples were measured using enzyme-coupled reactions and electrochemical detection in a YSI 2700 Select Bioanalyzer (YSI Life Sciences, Yellow Springs, OH, USA). Ammonium quantification was performed by an enzymatic-colorimetric method at 340 nm (EnzyChrom ${ }^{\mathrm{TM}}$ Ammonia/Ammonium Assay Kit (ENH3-100), BioAssay Systems, Hayward, CA, USA). 


\section{Statistical regression model}

Linear models for predicting viable cell concentrations $\left(X_{\mathrm{v}}\right)$ from ammonium $(\mathrm{A})$, glucose $(\mathrm{G})$, glutamine $(\mathrm{Q})$ and lactate $(\mathrm{L})$ concentrations were calibrated using linear multiple regressions. The generalized linear models are of the form described by Eqn. 1:.

$$
\operatorname{Ln}\left(X_{v}\right)=b_{0}+b_{A} A+b_{G} G+b_{Q} Q+b_{L} L+\varepsilon
$$

where $b_{0}$ and $b_{\mathrm{i}}$ represent the independent and partial regression coefficients of each nutrient or metabolite concentration, respectively, and $\varepsilon$ is the residual difference between observed and predicted viable cell concentrations. Partial regression coefficients were estimated by means of the least squares method. Prediction capacities of statistical models were assessed with a significance level of $0.05(\alpha=0.05)$ and the coefficient of determination for each model was also defined. All statistical procedures and tests for this modeling approach were performed in Statgraphics Plus 5.0 software (Statistical Graphics Corporation, VA, USA).

\section{Logistic model for growth}

Verhulst's model (logistic model), represented in Eqn 2 and its integrated form (Eqn. 3), was adjusted to describe the viable cell concentration over the time course of exponential growth, deceleration and stationary phases of a typical batch growth pattern (Liu, 2013) . In addition, the time $\left(t_{\mathrm{m}}\right)$ for reaching maximum cell concentration $\left(X_{v \max }\right)$ was defined by inspection of the experimental data.

$$
\begin{gathered}
\frac{d X_{v}}{d t}=k X_{\nu}\left(1-\frac{X_{\nu}}{X_{\nu \infty}}\right) \\
X_{v}(t)=\frac{X_{\nu \infty}}{1+\left(\frac{X_{v \infty}-X_{\nu 0}}{X_{\nu 0}}\right) e^{-k t}}
\end{gathered}
$$

The two parameters of this model, $\mathrm{k}$ (intrinsic growth rate constant, $\mathrm{h}^{-1}$ ) and $X_{v \infty}$ (cell density level in the medium, cells $\mathrm{L}^{-1}$ ), were determined by curve fitting (nonlinear least squares method) of the integrated Verhulst's model in Matlab R2012a (MathWorks Inc, Natick, MA, USA).

The starting values of $\mathrm{k}$ and $X_{v o}$ necessary for the selected curve fitting method were defined by plotting $\left(\frac{1}{X_{v}} \frac{d X_{v}}{d t}\right)$ vs $X_{v}$ (graphical method derived from Eqn [2]); a linear trend line was fitted to the data in Microsoft Office Excel 2007 (Microsoft Corporation, Redmond, Wash, USA); $X_{v \infty}$ and k starting values correspond to the intercepts at the $\mathrm{x}$-axis and $\mathrm{y}$-axis, respectively. The instantaneous growth rate $\left(\frac{d X_{v}}{d t}\right)$ was determined by a geometrical approach (Leduy and Zajic, 1973).

\section{Mechanistic mathematical model (Monod-Type Kinetics)}

The mechanistic mathematical model for describing growth and metabolism in experiments performed using the batch operation mode consisted of six first-order ordinary differential equations, which represent the rate of change of viable and dead $\left(X_{D}\right)$ cell concentrations as well as nutrients and metabolites (Eqn. 4-9).

$$
\begin{gathered}
\frac{d X_{v}}{d t}=\left(\mu-k_{d}\right) X_{v} \\
\frac{d X_{D}}{d t}=k_{d} \cdot X_{v}-K_{L Y S I S} X_{D} \\
\frac{d G}{d t}=\left(-\frac{\mu}{Y_{X / G}}-m_{G}\right) X_{v} \\
\frac{d Q}{d t}=\left(-\frac{\mu}{Y_{X / Q}}-m_{Q}\right) X_{v}-k_{d \cdot Q} Q \\
\frac{d L}{d t}=-Y_{L / G}\left(-\frac{\mu}{Y_{X / G}}-m_{G}\right) X_{v} \\
\frac{d A}{d t}=-Y_{A / Q}\left(-\frac{\mu}{Y_{X / Q}}-m_{Q}\right) X_{v}+k_{d \cdot Q} Q
\end{gathered}
$$

The glucose depletion rate considered both the consumption of this nutrient for growth and the maintenance of viable cells (the $\frac{\mu}{Y_{X / G}}$ and $m_{G}$ terms of Eqn 6) (Pirt 1982). The rate of glutamine consumption represented in Eqn 7 was modeled similarly to glucose depletion, but chemical degradation of glutamine to ammonium under the culture conditions was equally considered by means of the firstorder coefficient, $k_{d, Q}$ (Ozturk \& Palsson, 1990). All lactate produced was assumed to be due to consumption of glucose (Eqn 8). Ammonium production comprised glutamine consumption and chemical degradation of glutamine (Eqn 9).

The specific growth rate $(\mu)$ was described by considering a Monod multiplicative model, which incorporates the effects of limiting substrates (glucose and glutamine) and inhibitory byproducts (lactate and ammonium) (Eqn 10). This Monod-type equation was successfully applied for modeling other mammalian cell lines (Craven et al., 2013; Kompala, 2013). Cell death rate $\left(k_{d}\right)$ was modeled according to a kinetic expression previously reported (Liu et al., 2008).This parameter 
depends on the maximum death rate $\left(k_{d \cdot \max }\right)$, intrinsic death rate $\left(k_{u}\right)$ and specific growth rate (Eqn 11).

$$
\begin{gathered}
\mu=\mu_{\max } \frac{G}{K_{G}+G} \cdot \frac{Q}{K_{Q}+Q} \cdot \frac{K_{L}}{K_{L}+L} \cdot \frac{K_{A}}{K_{A}+A} \\
k_{d}=k_{d \cdot \max } \cdot\left(\frac{k_{u}}{\mu+k_{u}}\right)
\end{gathered}
$$

An analysis of degrees of freedom was performed in order to find a unique solution for this modelling approach. The sum of independent differential (6) and algebraic (2) equations, eight equations in total, was equal to the number of state and auxiliary algebraic variables $\left(\mu, k_{d}\right)$. Consequently, the degree of freedom was 0 . The number of model parameters was 15 . Then, a unique solution was possible by the definition of these parameters (Hangos and Cameron, 2001).

To fit this mechanistic model the fifteen parameters were determined. As a rule, five of them $\left(Y_{X / G}, Y_{X / O}\right.$, $\left.Y_{L / G}, Y_{A / Q} \mu_{\max }\right)$ were defined experimentally and the remaining parameters $\left(k_{d, \max }, k_{u}, K_{L Y S I S}, K_{d, Q}, K_{G}, K_{Q}\right.$, $\left.K_{L}, K_{A}, m_{G}, m_{Q}\right)$ were fitted using the genetic algorithm technique with constraints based on a literature survey. In experiments with significant death cell phase, $k_{d \max }$ was also calculated experimentally (Levenspiel, 1972).

The $\mu_{\max }$ was calculated by linear regression fitting in the exponential growth phase, plotting $\operatorname{Ln}\left(X_{v}\right)$ vs $\mathrm{t} ; \mu_{\max }$ is the slope of the line which represents the Malthus growth model (Liu, 2013). Yield ratios $\left(Y_{L / G}\right.$, $\left.Y_{X / Q}, Y_{X / G}, Y_{A / Q}\right)$ were determined by performing linear regression on plots of $X_{v}$ against $\mathrm{G} ; X_{v}$ against Q; L against $\mathrm{G}$ and $\mathrm{A}$ against $\mathrm{Q}$.

A code was created in Matlab for solving the system of six first-order ordinary differential equations mentioned above, using an ordinary differential equation solver (ODE23s). The parameters to be fitted were calculated through a genetic algorithm (genetic algorithm toolbox of MATLAB), whose objective function for minimization was the pondered sum of the squares of errors (PSSE) for each of the six state variables (Eqn 12) (Nandasana and Kumar, 2008). For the genetic algorithm the lower and upper bounds were defined for each variable (survey of the literature) (Craven et al., 2013), the maximum number of generation was 1000 , population type and size were double vector and 20, respectively. The selection function was stochastic uniform. For reproduction, mutation, crossover, migration, constraint parameters were chosen according to default values proposed by the genetic algorithm toolbox (MATLAB).

$$
\begin{aligned}
& P S S E=W_{X_{\nu}}^{2} \sum_{i=1}^{n}\left(X_{\nu p i}-X_{v e_{i}}\right)^{2}+ \\
& W_{X_{D}}^{2} \sum_{i=1}^{n}\left(X_{D p i}-X_{D e}\right)^{2}+ \\
& +W_{G}^{2} \sum_{i=1}^{n}\left(G_{p i}-G_{e_{i}}\right)^{2}+ \\
& W_{Q}^{2} \sum_{i=1}^{n}\left(Q_{p i}-Q_{e_{i}}\right)^{2}+ \\
& W_{L}^{2} \sum_{i=1}^{n}\left(L_{p i}-L_{e_{i}}\right)^{2}+ \\
& W_{A}^{2} \sum_{i=1}^{n}\left(A_{p i}-A_{e_{i}}\right)^{2}
\end{aligned}
$$

where $W_{X v}, W_{X D}, W_{G}, W_{Q}, W_{L}, W_{A}$ are the weighing factors, which were assumed to be the reciprocal of the maximum value of the respective state variable: $X$, $X_{D}, G, Q, L, A$. The subscripted terms with " $p$ " and " $e$ ", represent the predicted model and experimental values, respectively, for the corresponding state variable at the experimental point " $i$ ". The number of samples taken for each assessed set of operational conditions is represented by " $n$ ".

\section{Determination of relative model errors and coefficient of variation for model parameters}

The relative prediction errors of the three modeling approaches were determined by considering the maximum value of the state variable, being described as a reference value. The relative error for each point $\left(e_{r i}\right)$ was calculated according to Eqn 13 . The average $\left(e_{r}\right)$ and standard deviation (s.d.) for all points corresponding to each state variable in a defined experiment were also calculated by Eqn 14 and Eqn 15 , respectively.

$$
\begin{gathered}
e_{r_{i}}=\frac{\left|x_{m}-x_{e}\right|}{x_{e \max }} \cdot 100 \\
\bar{e}_{r}=\frac{\sum_{i=1}^{n} e_{r_{i}}}{n} \\
\text { s.d. }=\sqrt{\frac{1}{n-1} \sum_{i=1}^{n}\left(e_{r i}-\bar{e}_{r}\right)^{2}}
\end{gathered}
$$

The coefficient of variation $(\mathrm{CV})$ of the model parameters was calculated when repetitions of the same experimental conditions were performed. The equation for this statistical index is represented in Eqn 16.

$$
C V=\frac{s . d . p}{\bar{p}} \cdot 100[\%]
$$

where, $\overline{\mathrm{p}}$, s.d. $_{p}$, represent the parameter average and standard deviation. 


\section{RESULTS}

In general, the viable cell concentration was similarly predicted by the three modeling approaches, taking into account the relative error values (Tables $1,2,3)$. Specifically, for statistical regression models, which describe this state variable, the coefficients of determination were higher than $91.84 \%$ and the average relative errors lower than $11.63 \%$ (Table 1 and Figure 1). High values of the independent partial regression coefficients $\left(b_{0}\right)$ were associated with high maximum cell concentrations reached in each set of experiments, classified by bioreactor configuration and $\mathrm{pH}$ control mode (Figures 1, 2, 3, 4). In most cases, the effect of glutamine and ammonium concentrations were inversely correlated to $\ln \left(X_{v}\right)$, unlike glucose and lactate concentration effects, which were directly correlated (Table 1). Furthermore, significant differences were observed for partial regression coefficients corresponding to repetitions of the same experimental conditions (Table 1).

The parameters of the logistic model to describe cell growth were also influenced by the operational conditions under study. The cell density level in the medium $\left(X_{v o}\right)$, the intrinsic growth rate constant $(k)$ and the time at which $X_{v, \max }$ occurs oscillated in the range of $1.85-5.39 \times 10^{9}$ cells L ${ }^{-1}, 0.0611-0.0834 \mathrm{~h}^{-1}$ and $52.75-89.93 \mathrm{~h}$, respectively. The highest values of $X_{v \infty}$ were reached in the Bioflo 110 at $30 \%$ air saturation with $\mathrm{NaHCO}_{3}$ solution addition for controlling $\mathrm{pH}$. The optimal dissolved oxygen concentration for maximum cell concentration was not the same for the two bioreactor configurations without $\mathrm{NaHCO}_{3}$ solution addition; 10 and $50 \%$ air saturation were the best values for Celligen and Bioflo 110, in this order (Table 2).

Table 1. Partial regression coefficients, R2 and relative error corresponding to statistical regression models (Eq. 1) for each assessed experimental condition.

\begin{tabular}{|c|c|c|c|c|c|c|c|c|c|}
\hline Bioreactor & $\begin{array}{c}\text { pH control mode } \\
\left(\mathrm{NaHCO}_{3} \text { addition) }\right.\end{array}$ & $\begin{array}{l}\text { Dissolved oxygen } \\
\text { concentration } \\
(\% \text { air saturation })\end{array}$ & $\boldsymbol{b}_{0}$ & $\boldsymbol{b}_{A}$ & $\boldsymbol{b}_{G}$ & $\boldsymbol{b}_{Q}$ & $\boldsymbol{b}_{L}$ & $\mathrm{R}^{2}$ & $\begin{array}{c}\text { Relative error }(\%) \\
{\left[\mathrm{e}_{\mathrm{r}} \pm \text { s.d. }\right]^{*}}\end{array}$ \\
\hline \multirow{8}{*}{ Bioflo 110} & \multirow{4}{*}{ No } & 10 & 9.386 & -0.061 & 0.362 & 0.228 & 0.362 & 95.56 & $8.38 \pm 7.89$ \\
\hline & & 30 & 13.849 & 0.497 & 0.151 & 0.229 & 0.205 & 97.50 & $8.04 \pm 6.44$ \\
\hline & & 50 & 14.717 & 0.177 & 0.249 & -0.571 & 0.230 & 99.03 & $4.46 \pm 4.93$ \\
\hline & & 70 & 11.408 & 0.425 & 0.409 & -0.777 & 0.177 & 91.84 & $8.55 \pm 9.13$ \\
\hline & \multirow{4}{*}{ Yes } & $30^{(1)}$ & 22.151 & -0.161 & 0.040 & -1.174 & 0.013 & 97.00 & $8.54 \pm 5.11$ \\
\hline & & $30^{(2)}$ & 20.940 & 0.388 & 0.034 & -0.777 & 0.021 & 99.76 & $2.85 \pm 2.89$ \\
\hline & & $50^{(1)}$ & 22.947 & -0.162 & 0.001 & -1.002 & -0.017 & 93.81 & $11.63 \pm 9.77$ \\
\hline & & $50^{(2)}$ & 18.186 & -0.116 & 0.157 & -0.835 & 0.127 & 99.99 & $2.88 \pm 7.04$ \\
\hline \multirow{3}{*}{ Celligen } & \multirow{3}{*}{ No } & 10 & 23.488 & -0.212 & -0.035 & -0.929 & -0.016 & 99.15 & $6.29 \pm 5.74$ \\
\hline & & 30 & 17.615 & -0.301 & 0.276 & -1.446 & 0.129 & 99.36 & $2.18 \pm 1.57$ \\
\hline & & 50 & 23.199 & -0.241 & -0.042 & -0.861 & -0.017 & 99.78 & $2.16 \pm 2.05$ \\
\hline
\end{tabular}

(1), (2)First and second repetition of the same experiment, respectively.

$* \bar{e}_{\mathrm{r}}$ and s.d. represent average and standard deviation of the relative error.

Table 2. Logistic equation model parameters and relative error (considering from inoculation to stationary phase of the growth curve) for each assessed experimental condition.

\begin{tabular}{|c|c|c|c|c|c|c|}
\hline Bioreactor & $\begin{array}{c}\text { pH control mode } \\
\left.\text { ( } \mathrm{NaHCO}_{3} \text { addition }\right)\end{array}$ & $\begin{array}{c}\text { Dissolved oxygen } \\
\text { concentration } \\
\text { (\% air saturation) }\end{array}$ & $\boldsymbol{X}_{v \infty}\left(\right.$ cells L $\left.{ }^{-1}\right)$ & $\boldsymbol{k}\left(\mathrm{h}^{-1}\right)$ & $\boldsymbol{t}_{\mathrm{m}}(\mathrm{h})$ & $\begin{array}{c}\text { Relative error }(\%) \\
{\left[\overline{\mathrm{e}}_{\mathrm{r}} \pm \text { s.d. }\right]^{*}}\end{array}$ \\
\hline \multirow{8}{*}{ Bioflo 110} & \multirow{4}{*}{ No } & 10 & $1.85 \times 10^{9}$ & 0.0834 & 53 & $7.56 \pm 3.90$ \\
\hline & & 30 & $3.74 \times 10^{9}$ & 0.0704 & 67 & $10.29 \pm 6.10$ \\
\hline & & 50 & $4.35 \times 10^{9}$ & 0.0778 & 68 & $5.08 \pm 3.71$ \\
\hline & & 70 & $2.28 \times 10^{9}$ & 0.0663 & 68 & $9.62 \pm 5.47$ \\
\hline & \multirow{4}{*}{ Yes } & $30^{(1)}$ & $5.39 \times 10^{9}$ & 0.0800 & 67 & $5.29 \pm 3.42$ \\
\hline & & $30^{(2)}$ & $5.01 \times 10^{9}$ & 0.0760 & 90 & $5.85 \pm 4.51$ \\
\hline & & $50^{(1)}$ & $4.17 \times 10^{9}$ & 0.0826 & 80 & $7.97 \pm 5.05$ \\
\hline & & $50^{(2)}$ & $4.64 \times 10^{9}$ & 0.0738 & 77 & $6.64 \pm 5.05$ \\
\hline \multirow{3}{*}{ Celligen } & \multirow{3}{*}{ No } & 10 & $4.64 \times 10^{9}$ & 0.0827 & 71 & $9.10 \pm 5.48$ \\
\hline & & 30 & $3.42 \times 10^{9}$ & 0.0740 & 67 & $5.93 \pm 2.92$ \\
\hline & & 50 & $3.72 \times 10^{9}$ & 0.0611 & 64 & $7.98 \pm 3.79$ \\
\hline
\end{tabular}

*e $_{\mathrm{r}}$ and s.d. represent average and standard deviation of the relative error. 
Table 3. Prediction relative errors associated with the Monod-type kinetic model for the six monitored state variables, grouped according to the bioreactor configuration and $\mathrm{pH}$ control modes.

\begin{tabular}{lccc}
\hline \multirow{2}{*}{ State variable } & \multicolumn{3}{c}{ Relative errors for set of experiments $(\%)$ [ $\overline{\mathrm{e}}_{\mathrm{r}} \pm$ s.d.] } \\
\cline { 2 - 4 } & Bioflo 110 without $\mathrm{NaHCO}_{3}$ addition & Bioflo 110 with $\mathrm{NaHCO}_{3}$ addition & ${\mathrm{Celligen} \mathrm{without} \mathrm{NaHCO}_{3} \text { addition }}$ \\
\hline $\mathrm{A}$ & $6.34 \pm 5.82$ & $10.94 \pm 14.22$ & $12.59 \pm 15.16$ \\
$\mathrm{G}$ & $5.10 \pm 4.15$ & $8.76 \pm 11.84$ & $4.11 \pm 3.93$ \\
$\mathrm{~L}$ & $5.96 \pm 6.15$ & $7.93 \pm 10.47$ & $3.68 \pm 3.51$ \\
$\mathrm{Q}$ & $4.58 \pm 5.55$ & $6.04 \pm 8.96$ & $5.79 \pm 8.93$ \\
$\mathrm{X}_{\mathrm{d}}$ & $3.81 \pm 6.38$ & $5.21 \pm 6.76$ & $5.13 \pm 7.03$ \\
$\mathrm{X}_{\mathrm{v}}$ & $7.99 \pm 8.06$ & $11.24 \pm 10.92$ & $8.26 \pm 8.55$ \\
\hline
\end{tabular}

The fifteen parameters of the Monod-type model, based on a multiplicative Monod-type model for specific growth rate, were determined using a genetic algorithm approach; most of them were also influenced by operational conditions (Table 4). In general, the six state variables were adequately modeled in most experimental assays (Figure 2-4).

As a rule, glutamine-to-cells and glucose-tocells yields were superior when relatively high cell concentrations were reached. Contrary effects for glutamine-to-ammonium and glucose-lactate yields were confirmed. The glucose maintenance coefficient was higher than the glutamine maintenance coefficient in most of the experimental conditions. The maximum growth and death rates were in the range of 0.049 $0.080 \mathrm{~h}^{-1}$ and $0.0022-0.0129 \mathrm{~h}^{-1}$, respectively (Table 4).

The ammonium saturation constant was lower than the lactate saturation constant for all assessed experimental combinations. However, a global pattern was not defined for the relations between glucose $\left(K_{G}\right)$ and glutamine $\left(K_{Q}\right)$ saturation constants. The experimental cell environment, defined by operational conditions, caused a glutamine chemical degradation, which could be measured by the degree of degradation of glutamine (a first-order kinetic coefficient). This parameter demonstrated the highest values for batch performed in the Celligen with 50\% air saturation and the Bioflo 110 with $30 \%$ air saturation, controlling $\mathrm{pH}$ with addition of base solutions (Table 4).

With regard to the prediction of viable cell concentration, the average relative errors of the related model were higher when $\mathrm{pH}$ was strictly controlled over the course of bioconversion (Table 3 ). Specifically, this state variable was significantly underestimated for experiments performed in the Bioflo 110 at $30 \%$ air saturation (Figure $3 \mathrm{~A}, \mathrm{D})$. The remaining state variables were appropriately fitted to the experimental data with predicted average relative errors between
3.68 and $12.59 \%$. The worst values were those related to ammonium concentration (Table 3 ).

In general, high variability was observed in the model parameters when experiments were performed in similar conditions (Table 5). Among the assessed models, the logistic model showed less variation in its parameters $(\mathrm{CV}<21 \%)$.

\section{DISCUSSION}

The BHK-21 cell line has multiple applications and is considered to be an important host for high valuable biotherapeutics; however, few published works have focused in its growth and metabolism modelling (Teixeira et al., 2005; Linz et al., 1997). The impact of operational conditions on model parameters have been even less explored in the technical literature, not only for this mammalian cell line, but also for others. The present work aimed at increasing the mathematical characterization of bioprocesses with this cell line and to assess models commonly applied to other mammalian cell lines. These kinds of efforts are stimulated by regulatory agencies for better understanding of pharmaceutical processes by means of their initiative $\mathrm{QbD}$. Moreover, they are useful from an industrial point of view because of the derived improvement in process control and optimization (Tomba et al., 2013).

The first of the three modelling approaches, the statistical regression models for describing viable cell concentration, have been recently utilized in different operational modes for $\mathrm{CHO}$ cells. This technique provides knowledge about the state of this variable based on nutrient (glucose and glutamine) and metabolites (ammonium and lactate) in culture broth by multiple linear regression. In order to enhance the fitting quality of the model, the original values of viable cells concentration are frequently transformed by a natural logarithm function (Craven et al., 2013). 


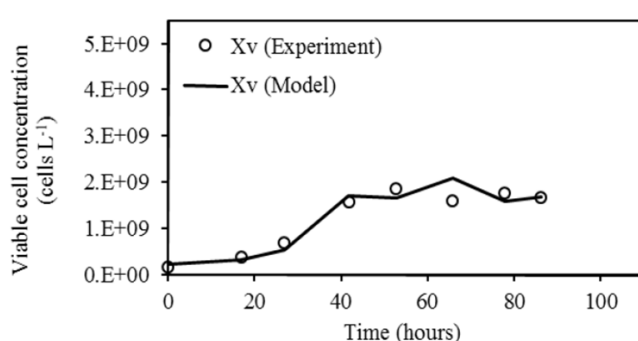

(A)

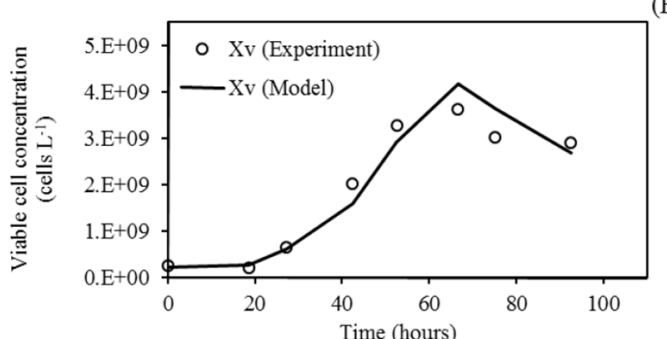

(B)

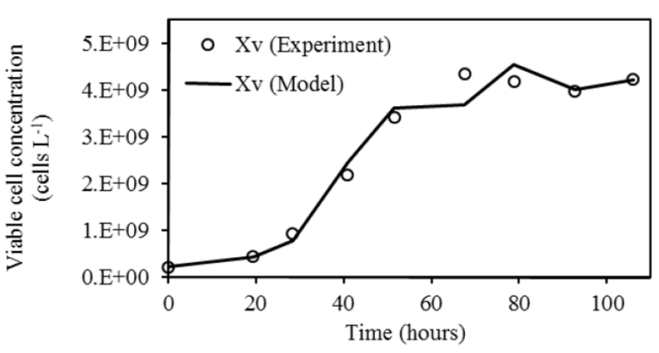

(C)

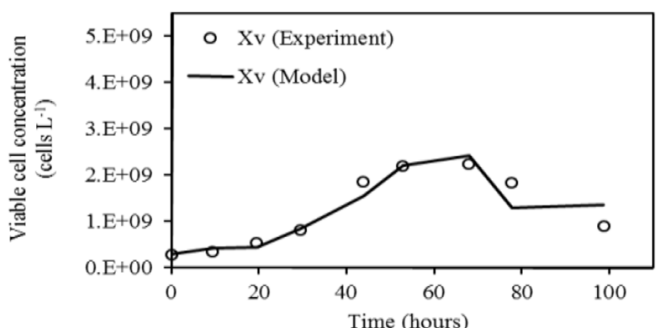

(D)

(E)
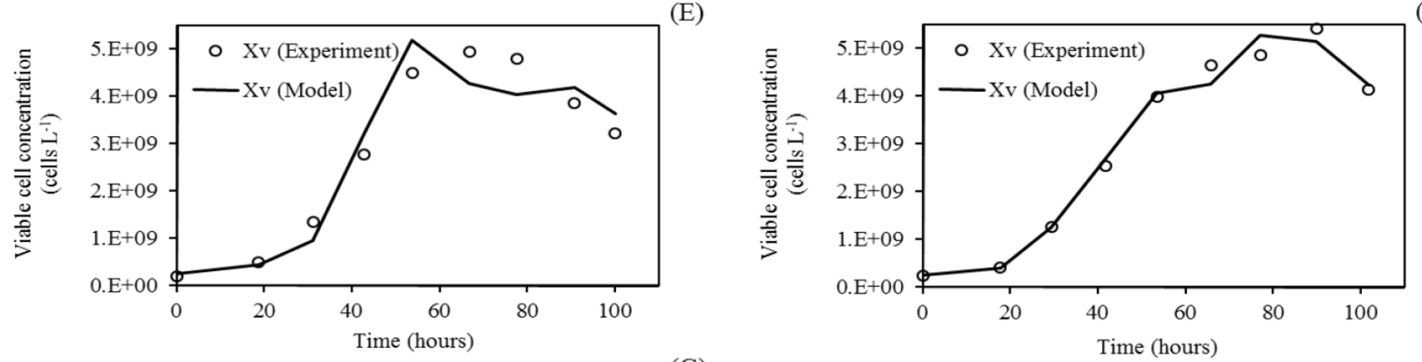

(G)
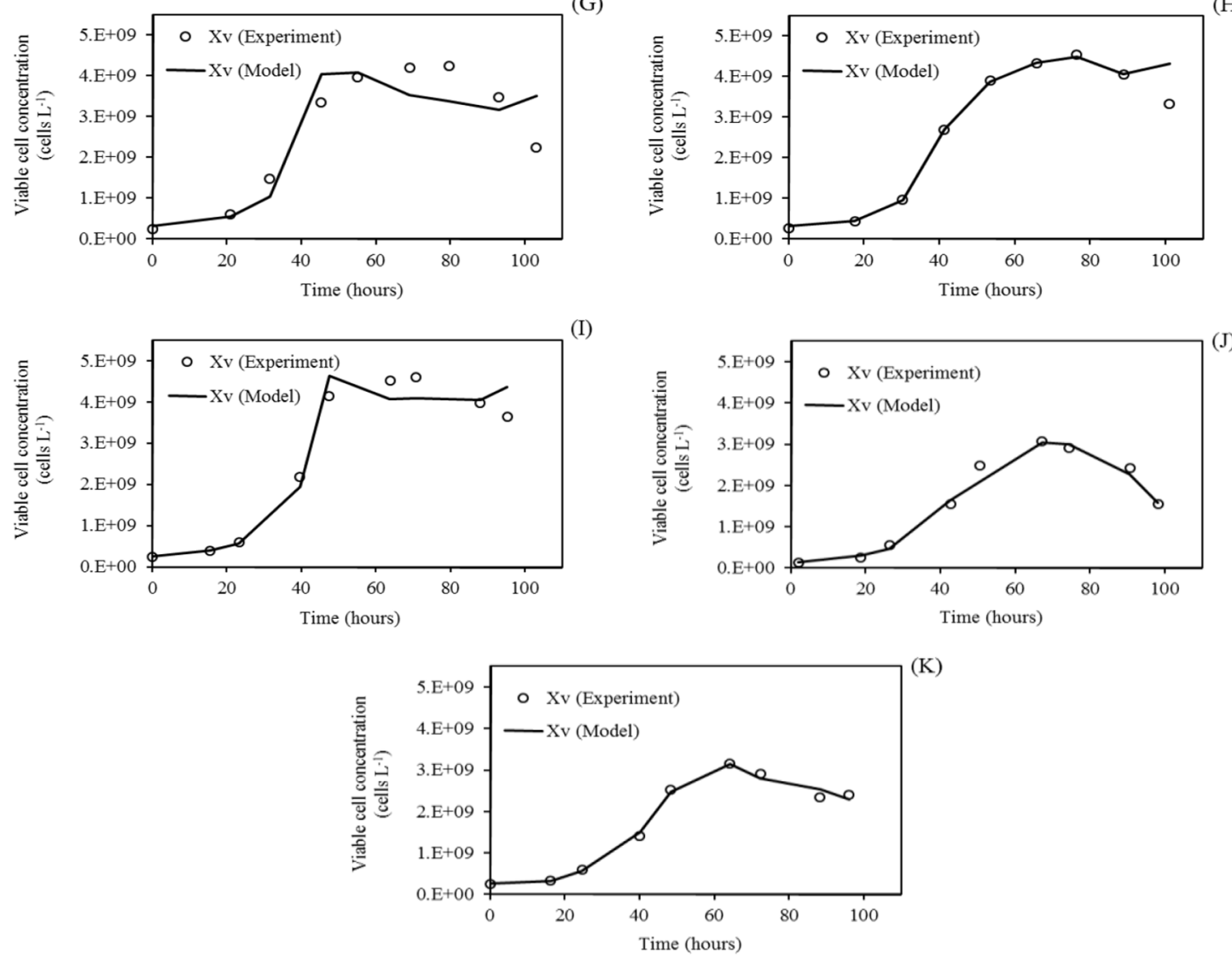

(K)

Figure 1. Statistical regression model predictions for viable cell concentration in the Bioflo 110 without $\mathrm{NaHCO}_{3}$ addition at different dissolved oxygen concentrations: (A) $10 \%$, (B) 30\%, (C) 50\%, (D) 70\% air saturation; in the Bioflo 110 with $\mathrm{NaHCO}_{3}$ addition at two dissolved oxygen concentration: (E) $30 \%$ air saturation, repetition 1, (F) 30\% air saturation, repetition 2, (G) 50\% air saturation, repetition 1, (H) 50\% air saturation, repetition 2; in Celligen without $\mathrm{NaHCO}_{3}$ addition at different dissolved oxygen concentrations: (I) $10 \%$, (J) $30 \%$, (K) $50 \%$ air saturation. 

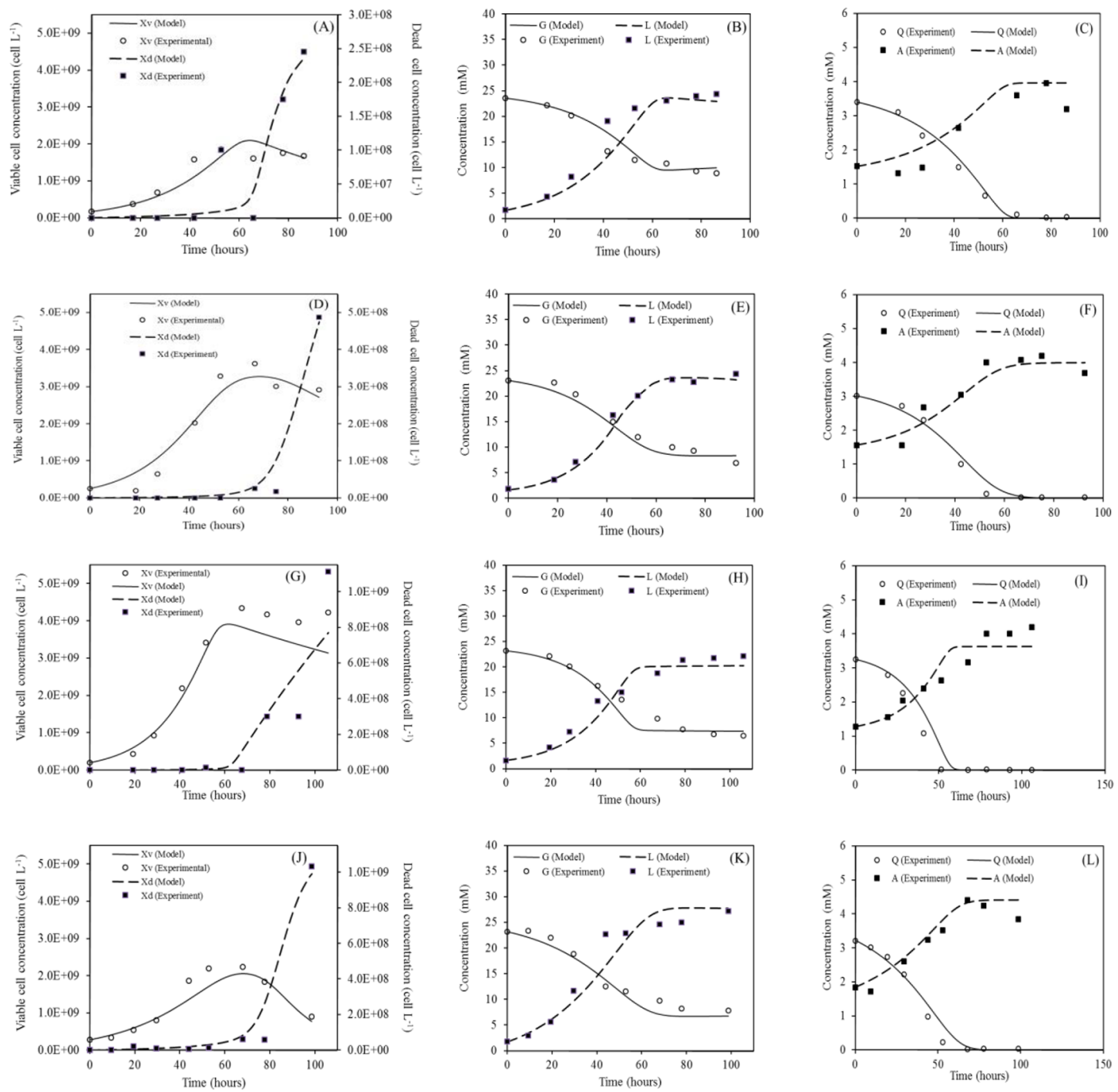

Figure 2. Monod-type kinetic model predictions for batch experiment performed in the Bioflo 110 without addition of $\mathrm{NaHCO}_{3}$ solution to control pH. A, $\mathrm{B}$, $\mathrm{C}$ correspond to predictions for state variables in batch experiment carried out at $10 \%$ air saturation. $\mathrm{D}, \mathrm{E}, \mathrm{F}$, correspond to predictions for state variables in batch experiment carried out at $30 \%$ air saturation. G, H, I, correspond to predictions for state variables in batch experiment carried out at $50 \%$ air saturation. $\mathrm{J}, \mathrm{K}, \mathrm{L}$, correspond to predictions for state variables in batch experiment carried out at $70 \%$ air saturation.

The absolute values for nutrient and metabolite regression coefficients of the present study for the BHK-21 cell line were similar to those reported for the $\mathrm{CHO}$ cell line, although discrepancies have been detected with respect to the corresponding signs of these regression coefficients in several cases (Craven et al., 2013). On the other hand, in this previous work, the maximum cell concentration in batch mode with rigorous control of $\mathrm{pH}$ during all the bioconversion, was inferior to $3 \times 10^{9}$ cells $\mathrm{L}^{-1}$, and the corresponding independent regression coefficient (16.652) in a statistical model was lower than those observed for experiments developed in similar conditions in the present work (Bioflo 110, pH control mode with
$\mathrm{NaHCO}_{3}$ addition) (Table 1-2). Thus, this parameter could be associated with the magnitude of cell growth, but it is sensitive to the $\mathrm{pH}$ control mode (Table 1-2). On the other hand, the negative sign for regression coefficients related to glutamine and ammonium concentrations, in relatively high cell concentrations, are reflecting the positive effect of this amino acid consumption and its associated metabolite generation, respectively, on cell growth. The capability to predict viable cell concentrations was satisfactory, taking into consideration that the expected error for cell counting by hemocytometer (method chosen for cell counting) is around 15\% (Hoffman, 2006). Thus, this kind of model could be used for monitoring BHK-21 cell cultures 

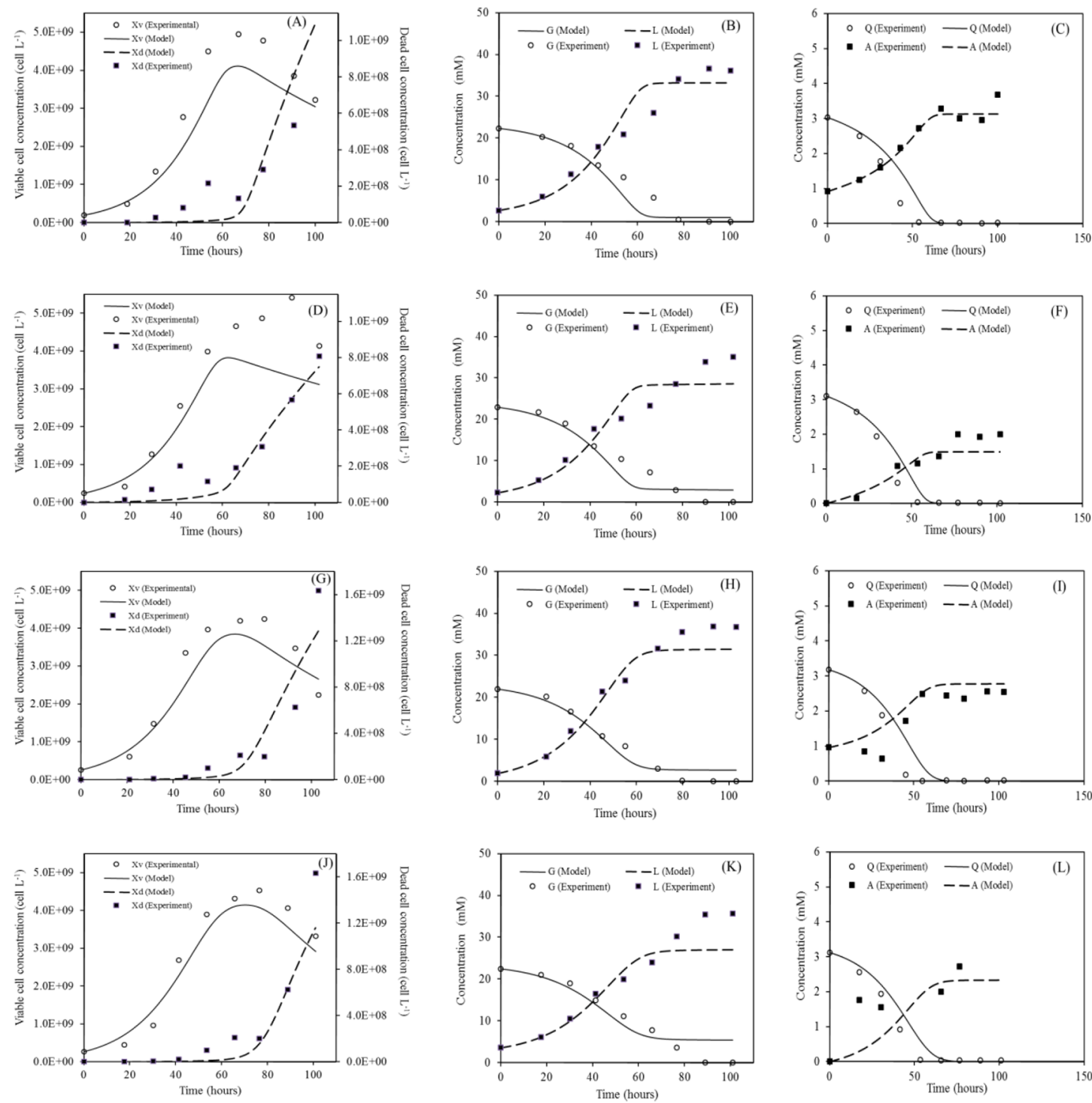

Figure 3. Monod-type kinetic model predictions for batch experiment performed in the Bioflo 110 with addition of $\mathrm{NaHCO}^{3}$ to control $\mathrm{pH}$. A, $\mathrm{B}$, C correspond to predictions for state variables in batch experiment carried out at $30 \%$ air saturation, repetition 1 . D, E, F, correspond to predictions for state variables in batch experiment carried out at 30\% air saturation, repetition 2. G, H, I, correspond to predictions for state variables in batch experiment carried out at $50 \%$ air saturation, repetition 1 . J, K, L, correspond to predictions for state variables in batch experiment carried out at $50 \%$ air saturation, repetition 2 .

by a combination of spectroscopy and chemometric methods. These techniques allow for determining online or at-line (sample withdrawn is analyzed quickly close to the bioreactor) chemical substances and, as a result, the viable cell concentration could be defined using statistical regression models (Leme et al., 2014).

The logistic model was the second model considered in this work. Original and modified logistic models have been used for modeling mammalian cell growth and metabolism (Craven et al., 2013; Goudar et al., 2005). The simple Verhulst's model for BHK21 growth was not extensively studied in different dissolved oxygen concentrations and bioreactor configurations. Analyzing the present results, it is possible to suggest $30 \%$ air saturation, with sharp $\mathrm{pH}$ control at 7.2 over the course of bioconversion for obtaining high BHK-21 cell concentrations in a classical stirred tank bioreactor. This statement is justified by the highest carrying capacity observed for the BHK-21 cells in the medium, among the different operational conditions considered. The intrinsic growth rate and the time at which the maximum viable cell concentration is reached were independent of operational conditions. This implies that proper environmental conditions in the bioreactor for cell growth and metabolism are established when the $\mathrm{pH}$ is well controlled around 7.2, and the growth phase is intensive or relatively prolonged. Moreover, these 

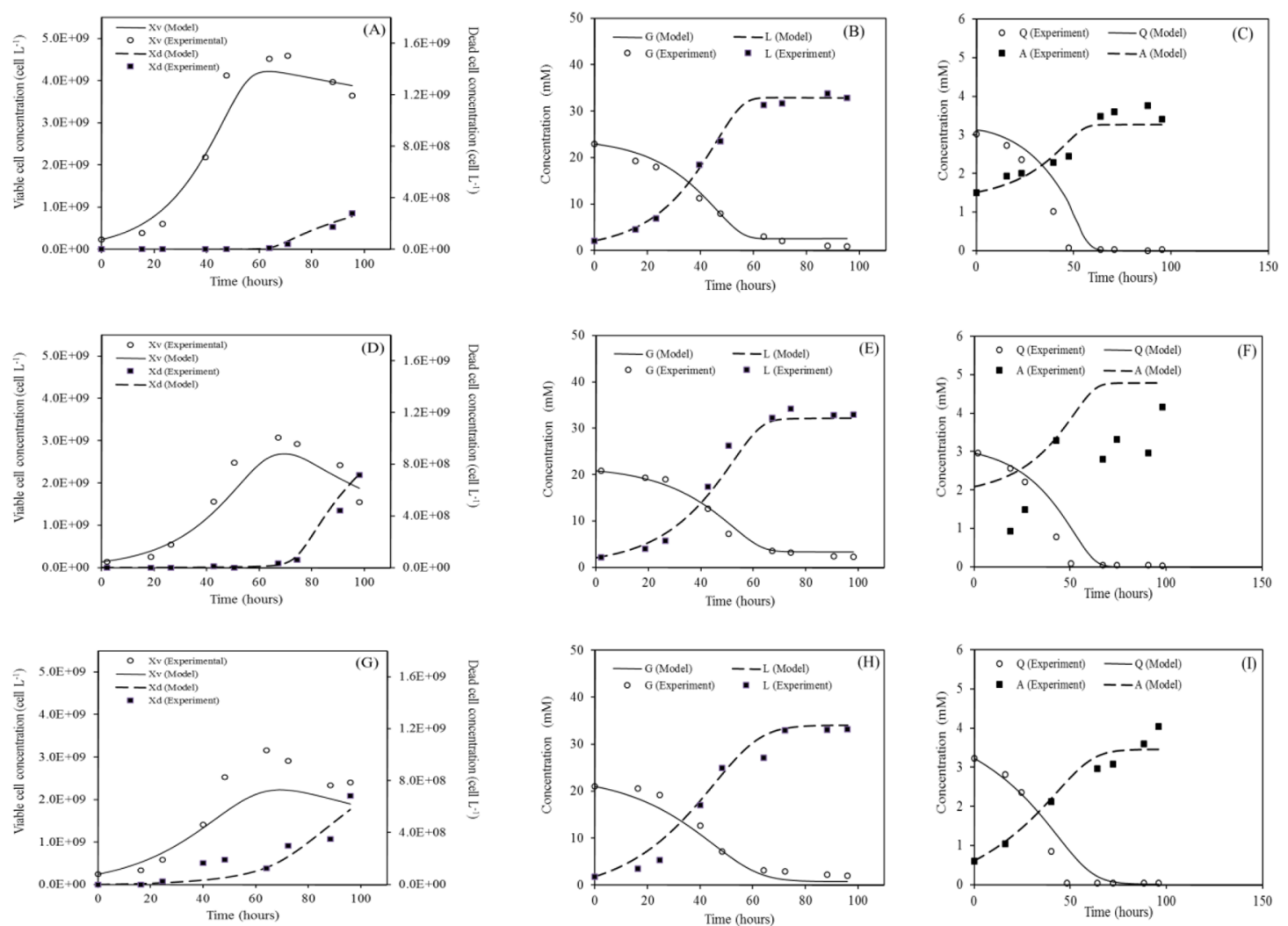

Figure 4. Monod-type kinetic model predictions for batch experiment performed in the Celligen without addition of $\mathrm{NaHCO}_{3}$ solution to control pH. A, $\mathrm{B}$, $\mathrm{C}$ correspond to predictions for state variables in batch experiment carried out at $10 \%$ air saturation. $\mathrm{D}, \mathrm{E}, \mathrm{F}$, correspond to predictions for state variables in batch experiment carried out at $30 \%$ air saturation. G, H, I, correspond to predictions for state variables in batch experiment carried out at $50 \%$ air saturation.

two latter parameters for BHK-21 cells were higher and lower, respectively, with respect to the observed values for these parameters in $\mathrm{CHO}$ cells (Craven et al., 2013). It is worthy to note that the culture media were different in both studies. The ability for viable cell concentration prediction using this modelling approach was also suitable.

With regard to the third assessed model, Monodtype kinetic models, similar values were detected for the respective parameters in a previous study with CHO cells (Craven et al., 2013). This finding could be interesting for bioprocess simulation of mammalian cell cultures. However, an underestimation of the viable cell concentration was observed in experiments with the highest cell concentrations, which could be explained by the need to assess other models that consider further growth after depletion of one of the limiting substrates. This fact is a limitation of the evaluated multiplicative Monod-model. An alternative could be the modified Monod-model proposed by Mankad and Bungay, which considers conventional Monod formulations and weighs the contribution of potentially limiting nutrients according to their halfsaturation constants (Mankad \& Bungay, 1988).
It is worth noting that several discrepancies in parameters associated with the three assessed models were detected for experiments performed in similar operational conditions with rigorous $\mathrm{pH}$ control over the course of bioconversion (Table 1-3, 5). This fact might be explained by the influence of inoculum quality on metabolism in cell culture carried out in bioreactors. It is an evidence of high batch to batch variability of the bioprocess in comparison to classical pharmaceutical process for small molecules.

It should be emphasized that the saturation constants $\left(K_{G}, K_{Q}, K_{L}, K_{A}\right.$ included in the Monodtype model have no physical meaning, as has been previously confirmed. These parameters were chosen arbitrarily to give the best fit for all state variables contained within this modelling approach (Shirsat et al., 2015). Moreover, the poor fit of the model for ammonium in the Monod-type strategy could be justified by the presence of amino acids and other proteins in the culture medium, which may have been metabolized or degraded chemically, generating toxic chemical compounds (Schneider et al., 1996). The incorporation of other differential equations describing 


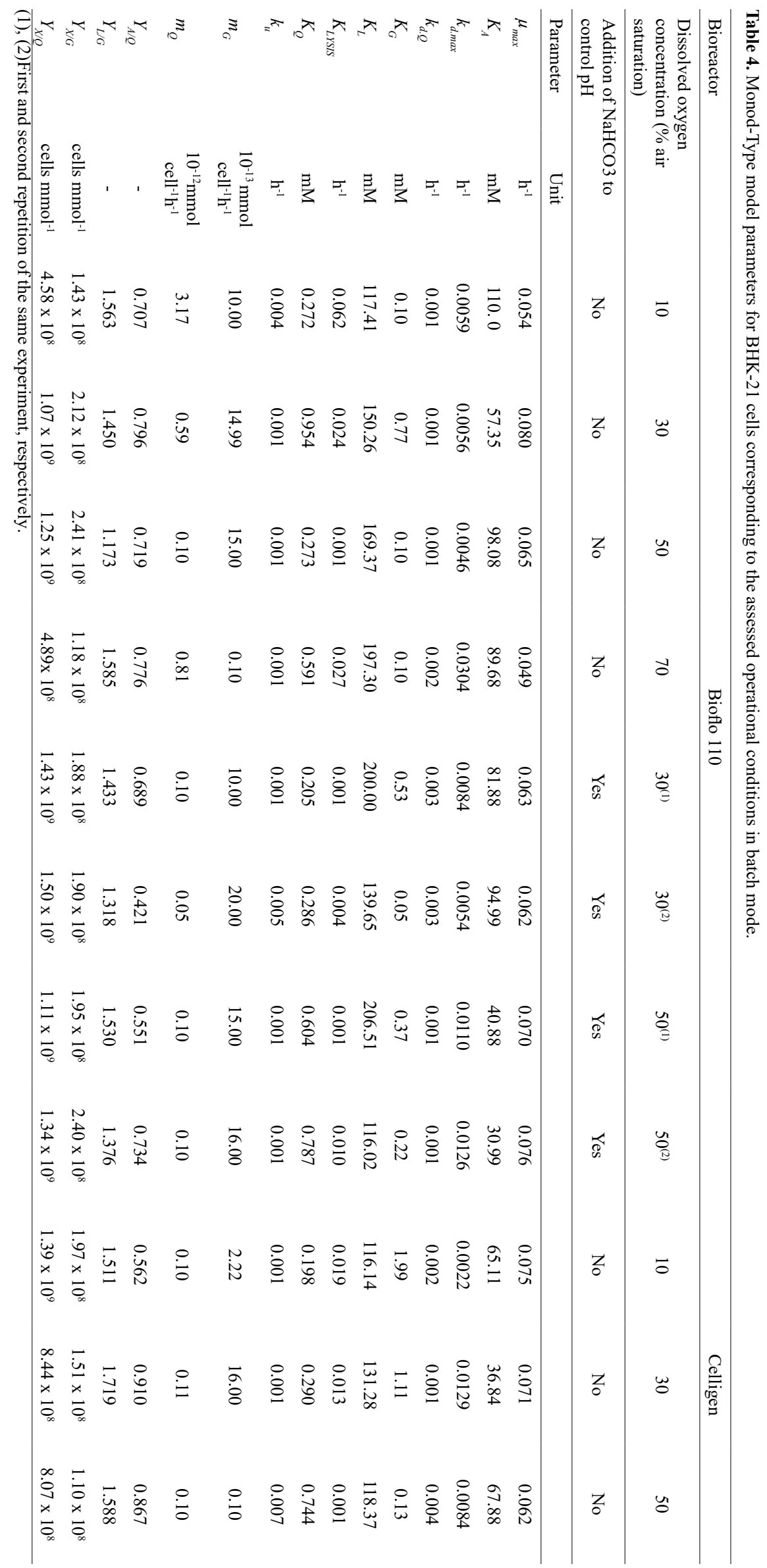


Table 5. Coefficients of variation for parameters associated with each assessed model, in experiments carried out in duplicate using the bioreactor Bioflo 110 .

\begin{tabular}{|c|c|c|c|}
\hline \multirow{3}{*}{ Model } & \multirow{3}{*}{ Parameter } & \multicolumn{2}{|c|}{ Coefficient of variation $[\%]$} \\
\hline & & \multicolumn{2}{|c|}{ Dissolved oxygen concentration ( $\%$ air saturation) } \\
\hline & & 30 & 50 \\
\hline \multirow{6}{*}{ Statistical regression } & $b_{0}$ & 3.97 & 16.37 \\
\hline & $b_{A}$ & 342.0 & 23.40 \\
\hline & $b_{G}$ & 11.47 & 139.6 \\
\hline & $b_{Q}$ & 28.78 & 12.86 \\
\hline & $b_{L}$ & 33.28 & 185.15 \\
\hline & $X_{v \infty}$ & 5.17 & 7.54 \\
\hline \multirow[t]{9}{*}{ Logistic equation } & $k$ & 3.63 & 7.96 \\
\hline & $t_{m}$ & 20.84 & 2.83 \\
\hline & $\mu_{\max }$ & 1.13 & 5.81 \\
\hline & $K_{A}$ & 10.48 & 19.46 \\
\hline & $k_{d \cdot \max }$ & 30.74 & 9.59 \\
\hline & $k_{d \cdot Q}$ & 0.00 & 0.00 \\
\hline & $K_{G}$ & 117.0 & 35.95 \\
\hline & $K_{L}$ & 25.13 & 39.68 \\
\hline & $K_{\text {LYSIS }}$ & 84.85 & 115.7 \\
\hline \multirow[t]{8}{*}{ Monod- Type } & $K_{Q}$ & 23.33 & 18.61 \\
\hline & $k_{u}$ & 94.28 & 0.00 \\
\hline & $m_{G}$ & 47.14 & 4.56 \\
\hline & $m_{Q}$ & 47.14 & 0.00 \\
\hline & $Y_{A / Q}$ & 34.14 & 20.14 \\
\hline & $Y_{L / G}$ & 5.91 & 7.49 \\
\hline & $Y_{X / G}$ & 0.75 & 14.63 \\
\hline & $Y_{X / Q}$ & 3.38 & 13.28 \\
\hline
\end{tabular}

these biochemical events could improve the prediction for this state variable.

The differences in the parameters of the Monodtype model for different operational conditions are probably the main consequence of environmental parameter changes such as dissolved oxygen and $\mathrm{pH}$. These variations could have an influence on cell metabolism inside the bioreactor. Monod-models, which include these effects, have been developed for microorganisms (Bhandari and Xia, 2005). They are complex and scarcely used in mammalian cell cultures.

The lack of an adaptation phase in the Monod models was not a problem and the experimental data could be fit by the Monod models assessed. This is probably a consequence of an insignificant adaptation phase (lag phase), guaranteed by the inoculum properties used, namely similar culture medium composition and moment of cell transfer within the growth curve (exponential phase) between scales (Figures 2-4).

The relatively high values of yield of cells from nutrients $\left(Y_{X / G}, Y_{X / Q}\right)$ were a numerical evidence in the Monod-type modelling strategy of the more suitable environmental conditions for cell growth. Moreover, yields of ammonium from glutamine were lower when relatively high maximum cell concentrations were reached, which is caused by the ammonium accumulation in culture broth. This metabolite is toxic for mammalian cells. However, the yield of lactate from glucose was independent of the operational conditions (Table 3, Figures 2-4). The higher glucose maintenance coefficients with respect to those for glutamine in most of the assessed conditions mean that the cells need higher quantities of glucose for cell maintenance (Craven et al., 2013; Núñez et al., 2013).

The glutamine degradation was favored at $30 \%$ air saturation of dissolved oxygen when the $\mathrm{pH}$ was strictly controlled. The highest value of $k_{d, O}$ was observed in this experimental condition. No patterns were observed for the maximum and intrinsic death rates as well as rate of cell lysis among the assessed experimental conditions. Nevertheless, the maximum specific growth rates were lower in experimental conditions that showed relatively low maximum cell concentrations (Bioflo-110, 10 and 
$70 \%$ air saturation without base addition for $\mathrm{pH}$ controlling).

In general, the conditions more favorable for BHK-21 growth were $30 \%$ air saturation with $\mathrm{NaHCO}_{3}$ solution addition for $\mathrm{pH}$ control, when bioconversion was performed in a classic stirred tank bioreactor (Bioflo 110). The criterion was maximum cell concentration, which was selected on the basis that this cell line is often used as a host for veterinarian viral vaccine, in which a high viable cell concentration in a short time is required. For all assessed experimental conditions, the time corresponding to maximum cell concentrations was around 72 hours. In the statistical regression model, the highest average independent regression coefficient was detected for these experimental conditions. In addition, the highest carrying capacity $\left(5.01-5.39 \times 10^{9}\right.$ cells L ${ }^{-1}$, Table 2) of the cells in the medium for the logistic model was identified. On the other hand, for the Monod-type kinetic model, the values for yield of cells from glutamine were the highest in this experimental arrange. Glutamine has been defined as the limiting substrate for the BHK-21 cell line (Núñez, et al., 2013).

Another important kinetic parameter to characterize cell growth, the maximum specific growth rate, was in the range of $0.06-0.08 \mathrm{~h}^{-1}$ in most of the assessed conditions for the BHK-21 cell line according to the Monod-type and logistic models (intrinsic growth rate constant is equivalent). The variability could be justified by the utilization of different dissolved oxygen concentrations, experimental noises or the dissimilar hydrodynamics of the assessed bioreactors.

As a rule, the three approaches under consideration demonstrated similar prediction quality with respect to the state variable, viable cell concentration (Table 1, 2, 4). However, the Monod-type kinetic modeling approach provides additional information about nutrients consumption and metabolite generation over the course of bioconversion. Thus, the Monod-type kinetic model is the only modelling approach under consideration in the present work, which allows systemically to describe elements of the cell metabolism and its relation with growth. In that sense, it is worth mentioning that the associated yield coefficients were defined as single values throughout the batch culture (this is accepted, though it can vary during cell growth curve). The statistical regression model could be used to model cell growth based on chemometric sensors, in which nutrient and metabolite concentrations can be defined. Nevertheless, the influence of bioconversion time is not considered in this model, which limits the mechanistic understanding of cellular metabolism. On the other hand, the fitted logistic models predicted the viable cell concentration up to the stationary phase, in terms of bioconversion time. The estimation of substrates and metabolites by logistic equations were not considered herein because these substrate and metabolite models would not be related simultaneously to cell growth. Thus, the relationship between cell metabolism and growth would not be described systemically. For the three models, the conditions of operation influenced the model parameters.

\section{CONCLUSIONS}

The present work defined the parameters associated with three modelling approaches for the kinetics of BHK-21 under different operational conditions and bioreactor configurations. These models find a wide application in biopharmaceutical processes using BHK-21 cells as host both from a regulatory and engineering point of view.

The fitted logistic and statistical models properly described viable cell concentrations in batch operation mode, but without characterizing the chemical and biological phenomena inside the bioreactor. Both modelling approaches could be applied at large scale to bioreactor culture in batch mode, with small adjustment of parameters, if scale-up criteria are properly chosen. On the other hand, the multiplicative Monod-type model was adequate for depicting the growth and metabolism dynamics and it can be used at large scale in bioreactors, even when operating in different operation modes.

\section{ACKNOWLEDGEMENTS}

The authors would like to thank the Fundação de Amparo à Pesquisa do Estado de São Paulo (FAPESP) for a postdoctoral fellowship (2010/52521-6) and Conselho Nacional de Desenvolvimento Científico 
e Tecnológico (CNPq: 483009/2010-5) for a scientific grant. The corresponding author gratefully acknowledges his wife, Relma and daughters, Giovanna and Paola, for the inspiration to write this article.

NOMENCLATURE

$A$ ammonium concentration (mM)

$A$ predicted ammonium concentra-

$A_{p i} \quad$ tion by the model at point $i(\mathrm{mM})$

$A$ experimental ammonium concentration at point $i(\mathrm{mM})$

ammonium partial regression

$b_{A} \quad$ coefficients $(-)$

$b$ glucose partial regression coeffi-

$b_{G} \quad$ cients $(-)$

$b_{L} \quad$ lactate partial regression coeffi-

$b_{L} \quad$ cients $(-)$

$b$ glutamine partial regression coe-

$b_{Q} \quad$ fficients $(-)$

$b$ independent partial regression coefficients $(-)$

CV coefficient of variation of model parameters $(\%)$

relative error for each point of

$e_{r i} \quad$ state variable under consideration

$\bar{e}_{r} \quad$ relative error average

$G \quad$ glucose concentration (mM)

$G \quad$ predicted glucose concentration

$G_{p i} \quad$ by model at point $i(\mathrm{mM})$

$G$ experimental glucose concentra-

$G_{e i} \quad$ tion at point $i(\mathrm{mM})$

sample identifier within sample set of each experiment $(-)$

intrinsic growth rate constant $\left(\mathrm{h}^{-1}\right)$ $k$ degree of degradation of glutamine $\left(\mathrm{h}^{-1}\right)$

$K_{L} \quad$ lactate saturation constant (mM)

$K$ ammonium saturation constant (mM)

$K$ glucose saturation constant (mM)

$K$ glutamine saturation constant (mM)

$k_{d} \quad$ death rate $\left(\mathrm{h}^{-1}\right)$

$k_{\text {d.max }} \quad$ maximum death rate $\left(\mathrm{h}^{-1}\right)$

$k_{u} \quad$ intrinsic death rate $\left(\mathrm{h}^{-1}\right)$

$K_{\text {LYSIS }} \quad$ rate of cell lysis $\left(\mathrm{h}^{-1}\right)$

$L \quad$ lactate concentration (mM)

predicted lactate concentration

$L_{p i}$

experimental lactate concentration at point $i(\mathrm{mM})$

glucose maintenance coefficient

$m_{G} \quad\left(\mathrm{mmol} \mathrm{cell} \mathrm{l}^{-1} \mathrm{~h}^{-1}\right)$

glutamine maintenance coeffi-

$m_{Q} \quad$ cient $\left(\mathrm{mmol}\right.$ cell $\left.{ }^{-1} \mathrm{~h}^{-1}\right)$

number of samples for specific

$n \quad$ experiment (-)

$\bar{p} \quad$ average of model parameters

PSSE pondered sum of the squares of the error $(-)$

Q glutamine concentration ( )

$Q$ predicted glutamine concentra-

$Q_{p i} \quad$ tion by the model at point $i(\mathrm{mM})$

$Q_{e i} \quad$ experimental glutamine concentration at point $i(\mathrm{mM})$

s.d. standard deviation of relative error s.d. $_{p} \quad \begin{aligned} & \text { standard deviation of model pa- } \\ & \text { rameters }\end{aligned}$ 
$t_{m} \quad$ time at which $X_{v \cdot \max }$ occurs (h) experimental value for a state

$x_{e} \quad$ variable within a kinetic experiment

maximum experimental value for

$x_{\text {e } \max }$ a state variable within a kinetic experiment

predicted value by a model for

$x_{m} \quad$ a state variable within a kinetic experiment

$X_{D} \quad$ dead cell density (cells $\mathrm{L}^{-1}$ ) predicted dead cell concentra$X_{D p i} \quad$ tion by the model at point $i$ (cells $\left.\mathrm{L}^{-1}\right)$

$X_{D e i}$

$X_{v}$

$X_{v p i}$

experimental dead cell concentration at point $i$ (cells $\mathrm{L}^{-1}$ )

viable cell density (cells L density (cells L-1)

predicted viable cell concentration by the model at point $i$ (cells $\mathrm{L}^{-1}$ )

$X_{v e i}$

experimental viable cell concentration at point $i$ (cells $\mathrm{L}^{-1}$ ) cell density level in the medium $X_{v \infty}$

$Y_{A / Q}$

$Y_{L / G}$

$Y_{X / G}$

$Y_{X / Q}$ (cells $\mathrm{L}^{-1}$ )

yield of ammonium from glutamine (-)

yield of lactate from glucose $(-)$ yield of cells from glucose (cells $\mathrm{mmol}^{-1}$ )

yield of cells from glutamine (cells $\mathrm{mmol}^{-1}$ )

$W_{A}^{::} \quad$ ammonium weighing factor $\left(\mathrm{mM}^{-1}\right)$

$W_{G}^{::} \quad$ glucose weighing factor $\left(\mathrm{mM}^{-1}\right)$

$W_{L}^{::} \quad$ lactate weighing factor $\left(\mathrm{mM}^{-1}\right)$

$W_{Q}^{::} \quad$ glutamine weighing factor
$W_{X_{\nu}}^{::} \quad \begin{aligned} & \text { viable cell weighing factor } \\ & \left(\text { cells }^{-1} \mathrm{~L}\right)\end{aligned}$

$W_{X_{D}}^{::} \quad$ dead cell weighing factor $\left(\right.$ cells $^{-1}$ L)

Greek Symbols

residual differences between ob-

$\varepsilon \quad$ served and predicted viable cell concentrations

$\mu \quad$ Specific growth rate $\left(\mathrm{h}^{-1}\right)$

$\mu_{\max }$

maximum specific growth rate $\left(\mathrm{h}^{-1}\right)$

\section{REFERENCES}

Auniņš, J. G., Viral Vaccine Production in Cell Culture. In: Encyclopedia of Industrial Biotechnology: Bioprocess, Bioseparation, and Cell Technology. Wiley, New York (2010).

Bhandari, A. and Xia, K., Fate of nitrogen compounds in animal waste lagoons. In: Animal Waste Containment in Lagoons, Viginia: American Society of Civil Engineering, p. 11 (2005).

Blanch, H.W. and Clark, D. S., Biochemical Engineering. Marcel Dekker, New York (1997).

Craven, S., Shirsat, N., Whelan, J. and Glennon, B., Process Model Comparison and Transferability Across Bioreactor Scales and Modes of Operation for a Mammalian Cell Bioprocess, Biotechnology Progress, 29, No. 1, 186 (2013).

Freshney, R. I., Culture of Animal Cells: A Manual of Basic Technique and Specialized Applications. 6th ed. Wiley-Blackwell, Hoboken (2010).

Goudar, C., Joeris, K., Konstantinov, K. and Piret, J., Logistic Equations Effectively Model Mammalian Cell Batch and Fed-Batch Kinetics by Logically Constraining the Fit, Biotechnology Progress , 21, No. 4, 1109 (2005).

Hangos, K. and Cameron, I., Process Modeling and Model Analysis. Academic Press, London (2001).

Hoffman, T. L., Chapter 3-Counting Cells . In: Celis, J.E., ed. Cell Biology. A Laboratory Handbook. Elsevier Academic Press, China, p. 21 (2006).

Kantardjieff, A. and Zhou, W., Mammalian Cell Cultures for Biologics Manufacturing. In: Mammalian Cell Cultures for Biologics Manufacturing. Springer, Heidelberg, p. 1 (2014). 
Kompala, D. S., Cell growth and protein expression kinetics. In: Upstream Industrial Biotechnology. John Wiley \& Sons, Inc., Hoboken, p. 85 (2013).

Kontoravdi, C., Samsatli, N.J. and Shah, N., Development and design of bio-pharmaceutical processes, Current Opinion in Chemical Engineering, 2, No. 4, 435 (2013).

Koutinas, M., Kiparissides, A., Pistikopoulos, E. and Mantalaris, A.,. Bioprocess Systems Engineering: Transferring Traditional Process Engineering Principles To Industrial Biotechnology. Computational and Structural Biotechnology Journal, 3, e201210022, doi: 10.5936/csbj.201210022 (2013).

Leduy, A. and Zajic, J., A geometrical approach for differentation of an experimental function at a point: Applied to growth and product formation, Biotechnology and Bioengineering, 15, No. 4, 805 (1973).

Leme, J. Fernández Núñez, E.G., de Almeida Parizotto, L., Chagas, W.A., Salla dos Santos, E., Tojeira Prestia Caricati, A., Gonçalves de Rezende, A., Labate Vale da Costa, B., Ventini Monteiro, D.C., Lopes Boldorini, V.L., Calil Jorge, S.A., Mancini Astray, R., Pereira, C.A., Pereira Caricati, C., Tonso, T., A multivariate calibration procedure for UV/VIS spectrometric monitoring of BHK21 cell metabolism and growth. Biotechnology Progress , 30, No. 1, 241 (2014).

Levenspiel, O., Chemical Reaction Engineering. 2nd ed. Wiley, New York (1972).

Linz, M., Zeng, A., Wagner, R. and Deckwer, W., Stoichiometry, kinetics, and regulation of glucose and amino acid metabolism of a recombinant BHK cell line in batch and continuous cultures, Biotechnology Progress , 13, No. 4, 453 (1997).

Liu, S., Chapter 11: How Cells Grow. In: Bioprocess Engineering. Elsevier, Amsterdam, p. 549 (2013).

Liu, Y.-H., Bi, J.-X., Zeng, A.-P. and Yuan, J.-Q., A simple kinetic model for myeloma cell culture with consideration of lysine limitation, Bioprocess and Biosystems Engineering, 31, No. 6, 569 (2008).

Mankad, T. and Bungay, H., Model for microbial growth with more than one limiting nutrient, Journal of Biotechnology, 7, No. 2, 161 (1988).

Nagashima, H. Watari, A., Shinoda, Y., Okamoto, H. and Takuma, S., Application of a Quality by Design Approach to the Cell Culture Process of
Monoclonal Antibody Production, Resulting in the Establishment of a Design Space, Journal of Pharmaceutical Sciences, 102, No. 12, 4274 (2013).

Nandasana, A.D. and Kumar, S., Kinetic modeling of lactic acid production from molasses using Enterococcus faecalis RKY1, Biochemical Engineering Journal, 38, No. 3, 277 (2008).

Núñez, E. G., Leme, J., de Almeida Parizotto, L., Chagas, W.A., de Rezende, A.G., da Costa, B.L., Monteiro, D.C., Boldorini, V.L., Jorge, S.A., Astray, R.M., Pereira, C.A., Caricati, C.P., Tonso, A., Influence of aeration-homogenization system in stirred tank bioreactors, dissolved oxygen concentration and $\mathrm{pH}$ control mode on BHK-21 cell growth and metabolism. Cytotechnology, 66, No 4, 605 (2013).

Ozturk, S. S. and Palsson, B. O., Chemical Decomposition of Glutamine in Cell Culture Media: Effect of Media Type, $\mathrm{pH}$, and Serum Concentration, Biotechnology Progress, 6, No. 2, 121 (1990).

Palomares, L.A. and Ramírez, O.T., Bioreactor ScaleUp. In: Encyclopedia of Industrial Biotechnology. Wiley-Blackwell, New York, p. 1 (2009).

Pirt, S., Maintenance Energy: a General Model for Energy-Limited and Energy-Sufficient Growth, Archives of Microbiology, 133, No. 4, 300 (1982).

Pörtner, R., Preface/ Foreword. In: Animal Cell Biotechnology. Methods and Protocols. 3rd ed.: Humana Press, Heidelberg, p. v (2014).

Schneider, M., Marison, I.W. and von Stockar, U., The importance of ammonia in mammalian cell culture, Journal of Biotechnology , 46, No. 3, 161 (1996).

Shirsat, N., Mohd, A., Whelan, J., English, N.J., Glennon, B. and Al-Rubeai, M., Revisiting Verhulst and Monod models: analysis of batch and fed-batch cultures, Cytotechnology , 67, No. 3, 515 (2015).

Streefland, M., Martens, D.E., Beuvery, E.C. and Wijffels, R.H., Process analytical technology (PAT) tools for the cultivation step in biopharmaceutical production, Engineering in Life Sciences, 13, No. 3, 212 (2013).

Teixeira, A., Cunha, A.E., Clemente, J.J., Moreira, J.L., Cruz, H.J., Alves, P.M., Carrondo, M.J. and Oliveira, R., Modelling and optimization of a recombinant BHK21 cultivation process using hybrid grey-box systems, Journal of Biotechnology , 118, No. 3, 290 (2005). 
Tomba, E., Facco, P., Bezzo, F. and Barolo, M., Latent variable modeling to assist the implementation of Quality-by-Design paradigms in pharmaceutical development and manufacturing: A review, International Journal of Pharmaceutics, 457, No. 1, 283 (2013).
Zhu, J., Mammalian cell protein expression for biopharmaceutical production, Biotechnology Advances, 30, No. 5, 1158 (2012). 